\title{
Runout of rock avalanches limited by basal friction but controlled by fragmentation
}

\author{
by $\varnothing$. T. Haug ${ }^{1,2}$, M. Rosenau ${ }^{1}$, M. Rudolf ${ }^{1}$, K. Leever ${ }^{1,3}$, and O. Oncken ${ }^{1}$
}

${ }^{1}$ GFZ German Research Centre for Geosciences, Helmholtz Centre Potsdam, Telegrafenberg, 14473 Potsdam, Germany.

${ }^{2}$ Njord center, Department of Geosciences, University of Oslo, PO Box 1048, 0316 Oslo, Nporway.

${ }^{3}$ Van Hall Larenstein University of Applied Sciences, Larensteinselaan 26a, 6882 Velp, The

Netherlands.

Correspondence: Matthias Rosenau (rosen@gfz-potsdam.de)

This version of the manuscript has been submitted to EGU Earth Surface Dynamics Discussions and has not undergone peer review (pre-print). A revised version has been accepted and published as:

Haug, Ø. T., Rosenau, M., Rudolf, M., Leever, K., and Oncken, O.: Short communication: Runout of rock avalanches limited by basal friction but controlled by fragmentation, Earth Surf. Dynam., 9, 665-672, https://doi.org/10.5194/esurf-9-665-2021, 2021

(open access)

() 2021.

This manuscript version is made available under the CC-BY-NC-ND 4.0 license

http://creativecommons.org/licenses/by-nc-nd/4.0/ 


\title{
Short communication: Runout of rock avalanches limited by basal friction but controlled by fragmentation
}

\author{
Øystein. T. Haug ${ }^{1,2}$, Matthias Rosenau ${ }^{1}$, Michael Rudolf ${ }^{1}$, Karen Leever ${ }^{1,3}$, and Onno Oncken ${ }^{1}$ \\ ${ }^{1}$ GFZ German Research Centre for Geosciences, Helmholtz Centre Potsdam, Telegrafenberg, 14473 Potsdam, Germany. \\ ${ }^{2}$ Njord center, Department of Geosciences, University of Oslo, PO Box 1048, 0316 Oslo, Norway. \\ ${ }^{3}$ Van Hall Larenstein University of Applied Sciences, Larensteinselaan 26a, 6882 Velp, The Netherlands.
}

Correspondence: Matthias Rosenau (rosen@gfz-potsdam.de)

\begin{abstract}
Rock avalanches display exceptionally long runouts, which are found to correlate with their volume and attributed to size dependent dynamic lowering of the effective basal friction. However, even for similar volumes, runouts are seen to span several orders of magnitude suggesting additional controlling factors. Here, we here analyse experiments with analogue models of rock avalanches aimed at testing the role of dynamic fragmentation. We show that for a fixed low basal friction, the runout of experimental rock avalanches varies over two orders of magnitude and is determined by their degree of fragmentation while the basal friction acts only as an upper limiter. We interpret the runout's dependence on fragmentation to be controlled by the competition between mobility enhancing spreading and energy consuming internal friction. We formalize this competition into a scaling law based on energy conservation which shows that variation in the degree of fragmentation can explain the large variation in runout of rock avalanches seen in nature.
\end{abstract}

\section{Introduction}

With volumes larger than $10^{6} \mathrm{~m}^{3}$, and speeds reported at over $150 \mathrm{~km} / \mathrm{h}$ (Campbell, 1989), the destructive power of rock avalanches is unprecedented. They are exceptional hazards produced when very large rockslides disintegrate during transport (Hungr et al., 2013). The travel distance of the deposit front, or runout, is an important measure for their hazard assessment (Vaunat and Leroueil, 2002) and is generally found to be longer than their fall height (Hsü, 1975). This suggests low effective basal frictions $\mu_{e f f}$, which is usually attributed to either a reduced normal stress at the base (e.g. Kent, 1966; Shreve, 1968; Hsü, 1975; Melosh, 1979; Campbell, 1989) or a velocity dependent decrease of the friction coefficient (e.g. Wang et al., 2017).

Field observations of the displacement of rock avalanches is typically given by the ratio of vertical $(H)$ and horizontal $(L)$ distance from the deposit's front to the top of the main scarp. The resulting ratio

$\mu_{a p}=\frac{H}{L}$ 
is known as the Heim's ratio (Heim, 1882, as cited in Hsü, 1975) and serves as a proxy for $\mu_{e f f}$ when called the apparent coefficient of friction (Manzella and Labiouse, 2012). One of the best established, but perhaps least understood observations of rock avalanches, is the dependence of the Heim's ratio on volume: rockslides below a size of approximately $10^{6} \mathrm{~m}^{3}$ all have a relatively constant Heim's ratio of $\sim 0.4-0.7$, but for larger rockslides it decreases with volume, reaching values $<0.1$ for volumes larger than $10^{9} \mathrm{~m}^{3}$ (Lucas et al., 2014). This suggests a scale dependent mechanism of decreasing apparent friction with volume that is only relevant for large volumes (Davies and McSaveney, 1999). Whether the effective friction itself depends on size is uncertain, though analysis by Lucas et al. (2014) suggests that this is the case. Importantly, even when similar volumes are considered, runouts are seen to span several oders of magnitude suggesting additional controlling factors. The uncertainty lies in part in the fact that the runout is defined by the front of the deposits, and therefore contains the combined effect of both translation and spreading of the rock mass. The additional travel distance caused by spreading can have a profound effect on the runout (Staron and Lajeunesse, 2009), especially if the effective basal friction is low.

Only recently, the process of dynamic fragmentation received increased attention and progress occurs in our understanding of its role in the dynamics of rock avalanches (Locat et al., 2006; Bowman et al., 2012; De Blasio and Crosta, 2015; Haug et al., 2016; Zhao et al., 2017, 2018; Lin et al., 2020; Gao et al., 2020; Knapp and Krautblatter, 2020). Firstly, one may expect that the finer the material, the more flow-like the behavior, increasing its mobility and allowing the rock mass to spread more easily (Locat et al., 2006; Wang et al., 2017; Zhao et al., 2018). Secondly, models of fragmenting rockslides suggest that dynamic fragmentation actively increases the spreading (Bowman et al., 2012; De Blasio and Crosta, 2015; Lin et al., 2020). However, fragmentation has also been shown to consume energy (Haug et al., 2016; Zhao et al., 2017; Lin et al., 2020), potentially at a cost to the runout length. Clearly, the integrated effect of fragmentation on the runout dynamics of rock avalanches remains to be specified.

40 In order to isolate the effects of friction and fragmentation on rock avalanche dynamics, we here analyse analogue models of dynamically fragmenting rock slides. Weassume that there exists some mechanism that causes a low, but constant effective coefficient of basal friction and keep it constant in our model. This entails that any experimentally observed variation in Heim's ratio is due to fragmentation. We describe the dependence observed between the runout and the degree of fragmentation in the form of a scaling law. Finally, we compare our experimental results to a set of natural data and discuss their relevance to natural systems. All data underlying this study as well as additional relevant data are published open access in Haug et al. (2020).

\section{Experimental methods}

In the experiments, originally documented in Haug et al. (2016), a block of height $h$ and length $l_{0}$ (width $=l_{0}$ ) of rock analogue material is gravitationally accelerated down a plate held at an angle of $45^{\circ}$ to the horizontal (Figure 1 ). After $1 \mathrm{~m}$ of travel, the sample impacts a horizontal plate causing it to fragment. Once the sample fragments have slide onto the horizontal plate, the fragments spread, decelerate due to internal and basal frictional contact and finally come to rest. We use silicate glass as our substrate, on which the basal friction coefficient is ca. 0.15 (Haug et al., 2016). The analogue rock material is a cemented fluvial quartz sand. The sand is cemented by mixing it with water and gypsum or potato starch, and is left to set for 2 days (for 


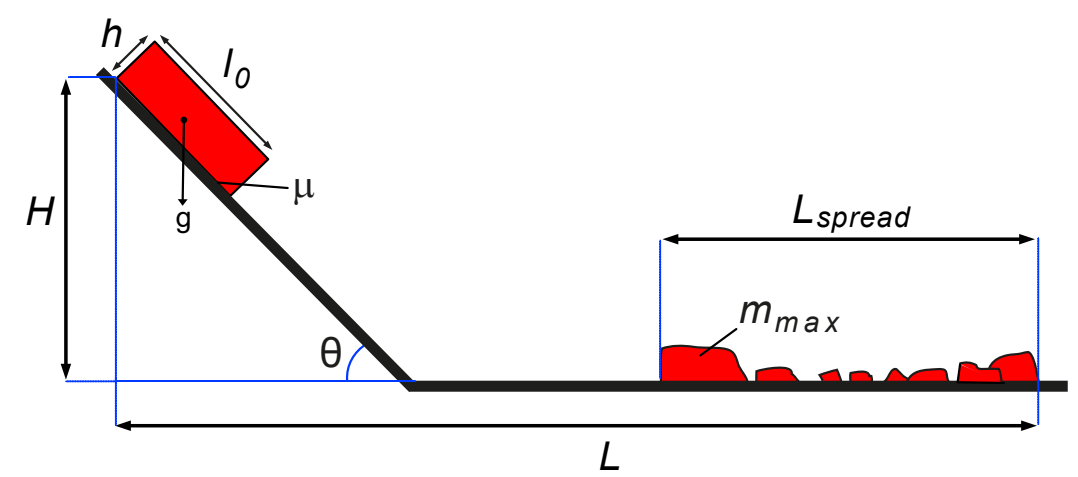

Figure 1. Sketch of the slope geometry of experiments and various length measurements (modified after Haug et al. (2016))

gypsum cement) or heated for 15 minutes in a $900 \mathrm{~W}$ microwave (for potato starch cement). The cohesion of the material can be controlled by the type and the amount of cement added to the mixture, allowing control on the strength of the material over several orders of magnitude. The internal friction coefficient relevant for fragmenting intact material is 0.7 and reduces to 0.6 when fragments interact (see Haug et al., 2014, 2016, for details on the experimental setup).

The three main observables from the experiments are: (i) the degree of fragmentation $\left(m_{c}\right)$, (ii) the Heim's ratio $(H / L)$ and (iii) the normalized deposit length $\left(L_{\text {spread }} / H\right)$. We characterize the degree of fragmentation through the total mass of the sample divided by the mass of the largest fragment $\left(m_{c}=M / m_{\max }\right)$, justification of which can be found in Haug et al.

60 (2016). The front (and back) of the deposit is determined by the mass-weighted average position of the most distal $5 \%$ of total mass. This defines a frontal rim which is a more robust runout estimate than using the foremost fragment position, used by Haug et al. (2016).

The experimental data analysed here stem from two series of experiments with varying degree of fragmentation: (i) one series of experiments where the the thickness to length ratio $\left(h / l_{0}=0.033-0.49\right)$ of the samples is varied while keeping the cohesion constant at $C=14 \mathrm{kPa}$. (ii) one series of experiments where the cohesion of the material is varied $(C=4-350 \mathrm{kPa})$ while keeping the thickness to length ratio constant at $h / l_{0}=0.13$. In both series of experiments, the fall height $(H)$ is kept constant at $0.71 \mathrm{~m}$. Interested readers are referred to Haug et al. (2016) for details on the effect of cohesion and geometry on the degree of fragmentation. Additionally, two new experiments were performed to study in detail the moment of fragmentation at high temporal resolution. For these experiments, the fragmentation of two samples with different cohesions but equal geometry $\left(C=4\right.$ and $\left.40 \mathrm{kPa}, h / l_{0}=0.13\right)$ is considered. These two experiments have a fall height of $0.35 \mathrm{~m}$, and data is captured by a camera with a frame rate of $500 \mathrm{~Hz}$ (see Haug et al., 2020, for movies of these experiments). 


\section{Results and discussion}

\subsection{Experimental observations and interpretation}

The Heim's ratio for experiments with different degrees of fragmentation $\left(m_{c}\right)$ is plotted in Figure 2a. The two series of experiments follow the same trend (Haug et al., 2016), and no distinction is made between them in this figure. It shows that the Heim's ratio decreases rapidly for low to intermediate degrees of fragmentation, reaching a minimum at $m_{c} \approx 5$ of about 0.2. With further increase of fragmentation a gentle increase in the Heim's ratio is observed. A similar behavior is observed for the length of the deposits (Figure $2 \mathrm{~b}$ ), which increase until $m_{c} \approx 5$ before it decreases for higher values.
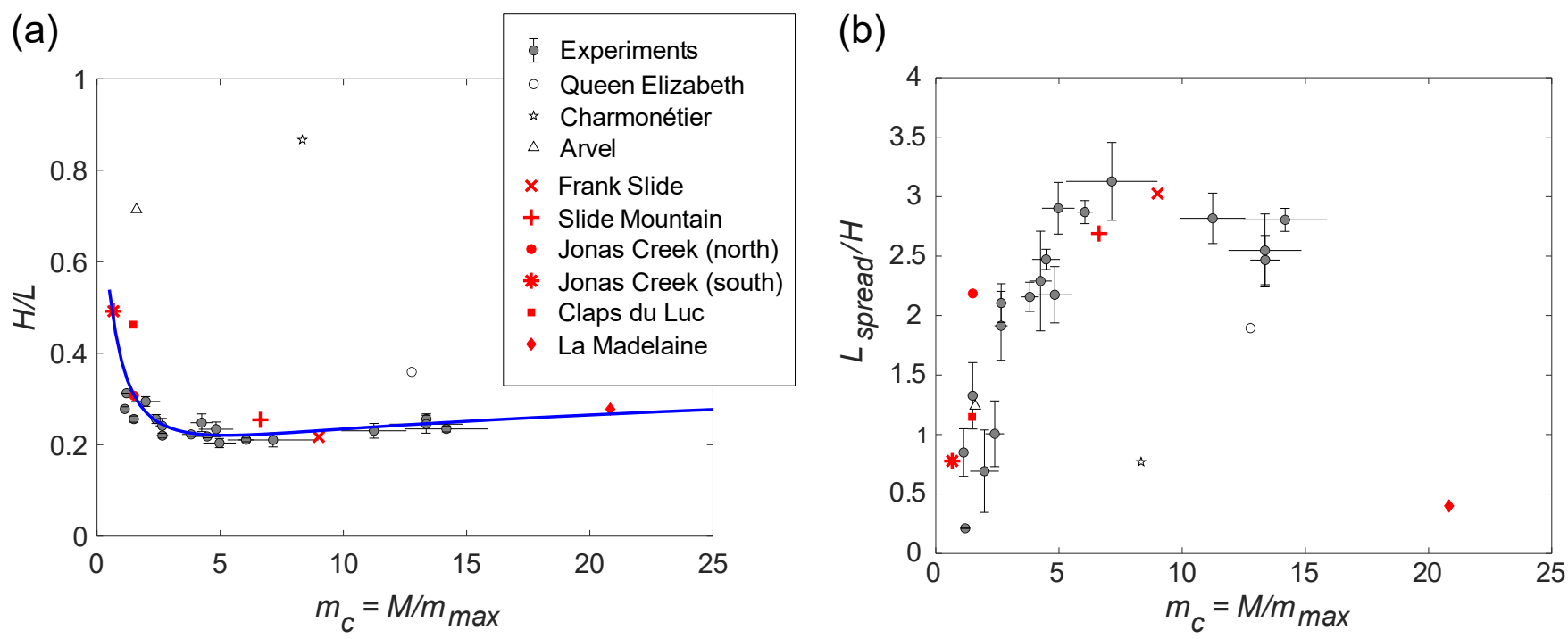

Figure 2. Heim's ratio and deposit length of experiments (this study) and natural rock avalanches (from Locat et al., 2006). (a) The Heim's ratio of the analogue experiments (gray) and from the rock avalanches (red $=$ selected set, open $=$ discarded). The blue line represents the best fit of Equation 7 to experimental and natural data with parameters $\alpha=0.11, \beta=1.0$ and $\gamma=1.5$. (b) The deposit's lengths. In both panels, the gray circles represent the average value of a set of 4-15 experiments and the error bars give the standard error of the set. Data shown and a Matlab-script to plot them are available in Haug et al. (2020).

Figure 3 presents snapshots from the two additional experiments. As expected, the sample with the highest cohesion (Figure 3a) is observed to fragment less than the one with a lower cohesion (Figure 3b). Accordingly, the fragments of the stronger sample spread with limited interaction while the fragments from the weaker sample collide and/or slide next to each other. As a consequence, a higher amount of internal deformation is experienced with increased fragmentation.

The rapidly decreasing Heims's ratio for $m_{c}<5$ observed in Figure 2a is likely caused by the increased spreading with fragmentation (Figure 2b). A similar result was also obtained by previous analogue experiments (Bowman et al., 2012; Haug et al., 2016) as well as numerical models (De Blasio and Crosta, 2015; Zhao et al., 2017). However, here we show that the Heim's ratio is not simply decreasing with the degree of fragmentation, but that it displays an optimum for $m_{c} \approx 5$. Impor- 


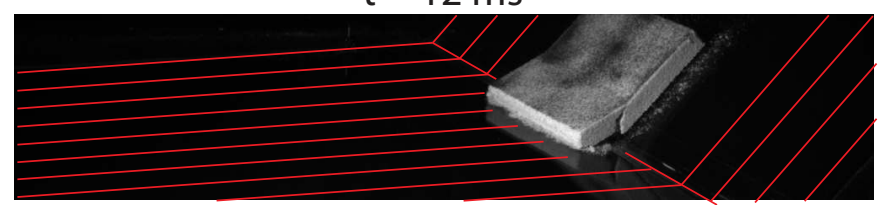

$\mathrm{t}=64 \mathrm{~ms}$

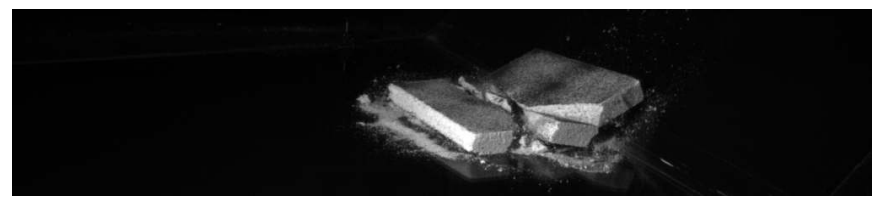

$\mathrm{t}=146 \mathrm{~ms}$

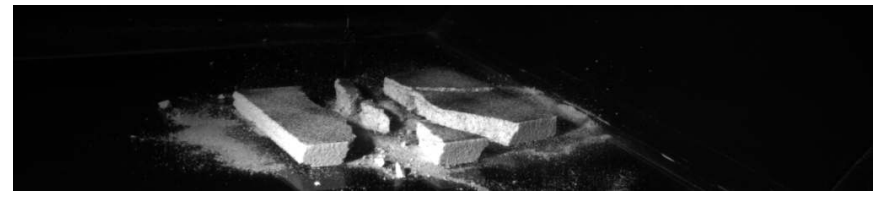

(a)

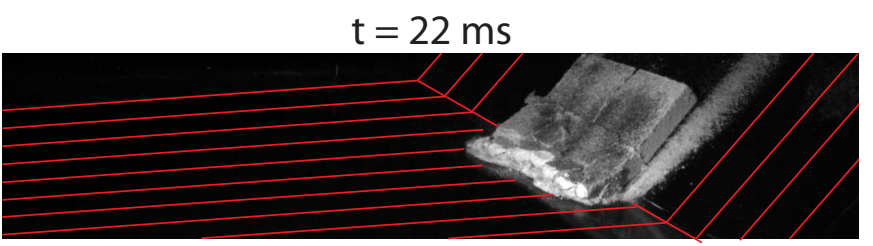

$\mathrm{t}=50 \mathrm{~ms}$

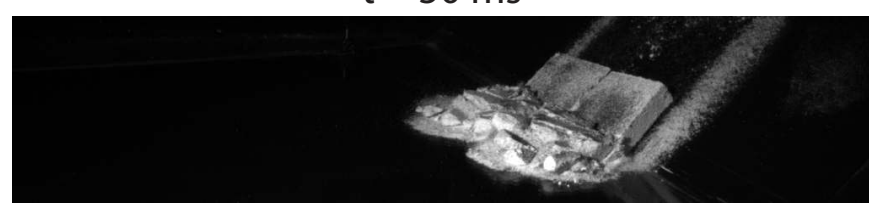

$\mathrm{t}=112 \mathrm{~ms}$

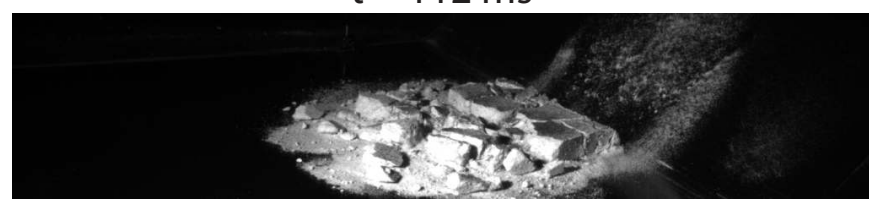

(b)

Figure 3. Snapshots from the experiments: (a) intermediate strength sample $(C=40 \mathrm{kPa})$ and (b) low strength sample $(C=4 \mathrm{kPa})$. The stronger sample (a) breaks apart into six large fragments with limited amount of fine material produced and move apart with little interaction after breaking. In contrast, the weaker sample fragments into many small pieces, with a large fraction of fine material, that interact more strongly. The red lines in the upper images indicate the geometry of the basal plates. The time given above each image reflects the time since first impact. The samples have dimensions $15 \times 15 \times 2 \mathrm{~cm}$. Movies of the experiments are available in Haug et al. (2020).

tantly, the lowest apparent basal friction, equivalent to the lowest Heim's ratio, is close to the implemented basal friction (i.e. friction coefficient of 0.15 between samples and glass). Therefore, all processes operating in our models (e.g. fragmentation, internal friction between fragments) tend to consume energy and thereby reduce runout from its optimum (Haug et al., 2016). Considering the increased internal deformation observed with the degree of fragmentation (Figure 3), the reduction of runout with $m_{c}>5$ appears to be the result of the increased energy dissipation through internal friction. Consequently, the minimum of the Heim's ratio observed in Figure $2 \mathrm{a}$ is the result of a competition between spreading and internal friction.

\subsection{A scaling law for runout}

The interplay between fragmentation and friction can be formalized into a scaling law by considering the conservation of energy. Generally, the conservation of energy of a sliding mass $M$ requires that

$M g H=\mu M g L_{p}+W$

where $g$ is the gravitational acceleration, $H$ is the vertical fall height, $L_{p}$ is the entire travel path of the slide and $W$ is the sum of any other energy dissipating terms. Here, we have assumed a Coulomb friction coefficient $\mu$ at the base. 
For the geometry of our experimental setup (i.e. Figure 1), and also roughly for the set of selected rock avalanches, the $L_{p}$ can be expressed in terms of the horizontal runout $L$ as

$L_{p}=L+L_{s}(1-\cos \theta)-\frac{1}{2} l_{0} \cos \theta-\frac{1}{2} L_{\text {spread }}$

where $L_{s}$ is the length and $\theta$ the angle of the slope, and $l_{0}$ is the initial length of the slide. It is assumed that the additional travel length due to spreading is equal to half the deposit length $\left(L_{\text {spread }}\right)$. Since $l_{0}$ is expected to be very small compared to the other terms, it is neglected in the further analysis. Inserting this expression into Equation 2 and solving for $L$ gives

$L=\frac{H}{\mu}-L_{s}(1-\cos \theta)+\frac{1}{2} L_{\text {spread }}\left(\mu, \phi, m_{c}, W\right)-W\left(\mu, \phi, m_{c}\right)$

where it is emphasized that both $L_{\text {spread }}$ and $W$ is expected to be functions of the basal friction, $\mu$, internal friction, $\phi$, the degree of fragmentation, $m_{c}$, as well as a possible non-linear dependence between $L_{\text {spread }}$ and $W$. With this expression for the runout, the Heim's ratio is

$\frac{H}{L}=\mu\left(1+\frac{\mu}{\sin \theta}(1-\cos \theta)+\frac{L_{\text {spread }}\left(\mu, \phi, m_{c}, W\right)}{2 H}-\frac{W\left(\mu, \phi, m_{c}, L_{\text {spread }}\right)}{M g H}\right)^{-1}$

A direct determination of the two last terms in Equation 5 is difficult, however, the experimental work by Haug et al. (2016), suggests that $W / M g h$ can be described with a logarithmic function of $m_{c}$. Additionally, based on the shape of both the Heim' ratio and the $L_{\text {spread }}$ plotted in Figure 2, it appears that it can be reasonably described by an exponential function of $m_{c}$. This leads to the approximation that

$$
\frac{L_{\text {spread }}\left(\mu, \phi, m_{c}\right)}{2 H}-\frac{W\left(\mu, \phi, m_{c}\right)}{M g H}=-\alpha \log \left(m_{c}\right)-\beta e^{-m_{c} / \gamma}
$$

110 such that the Heim's ratio can be expressed as

$\frac{H}{L}=\mu\left(1+\frac{\mu}{\sin \theta}(1-\cos \theta)-\alpha \log \left(m_{c}\right)-\beta e^{-m_{c} / \gamma}\right)^{-1}$

where $\alpha, \beta$, and $\gamma$ are constants to be empirically determined.

This equation describes the competition between spreading $\left(\beta e^{-m_{c} / \gamma}\right)$ and the increasing energy dissipation $\left(\alpha \log \left(m_{c}\right)\right)$ with $m_{c}$ and its relation to friction. A best fit of this function to the natural and experimental data is presented in Figure $2 \mathrm{a}$ (blue line), where $\alpha=0.11, \beta=1.0$ and $\gamma=1.5$. A fit to the experimental data only yields very similar results $(\alpha=0.11$,

$115 \beta=0.68$ and $\gamma=2.0$, see Figure A1). This suggests spreading dominates for low degrees of fragmentation (i.e. $m_{c}<5$ ), but has little effect at high degrees of fragmentation as the term $\beta e^{-m_{c} / \gamma}$ approaches zero. At high degrees of fragmentation, the energy dissipation related to fragmentation therefore becomes increasingly relevant. At $m_{c}=5$ a minimum is reached in which energy is consumed mainly by basal friction.

\subsection{Application to a natural data set}

120 We compare our experimental results (Figure 2) with data from nine rock avalanches reported by Locat et al. (2006), which show no clear volume dependence of runout. This makes this data set ideal to test whether a scale-independent process is operating besides dynamic basal weakening. However, not all the rock avalanches reported in (Locat et al., 2006) are comparable 
to our experimental setup by means of material properties and geometries (Figure 1). Based on slope geometry, the Queen Elizabeth slide is discarded because of its run-up on the opposite valley wall. Also discarded is the Charmonétier slide because of the sudden free fall stage at the end of its transport. Additionally, the Arvel slide was observed to bulldoze soft material in front of it, and such complexities are not considered in our models so this one is also neglected.

Figure 2 displays remarkably similar trends between the experimental and the selected natural data that all follow the proposed scaling law. The data points from Jonas Creek (north) and Clapse du Luc are observed to extend the trend from the experiments to higher Heim's ratio for low degrees of fragmentations while La Madelaine slide is observed to extend the trend of the experimental results of Heim's ratio to higher degrees of fragmentation (Figure 2a). Its low spreading value (Figure $2 b$ ) suggests that the reduction of spreading indicated by the experiments for $m_{c}>5$ continues for even higher degrees of fragmentation. The agreement between these slide deposit lengths and the extrapolation of the experimental trend through Equation 7 (Figure 2b) makes us confident about the validity and predictive power of our proposed scaling law. The Heim's ratios of the neglected slides are all, as expected, higher than the selected data set for their respective degrees of fragmentation, illustrating the importance of topography (e.g. opposite valley wall) and processes such as bulldozing.

The similarity seen between experimental and natural data suggests universality with respect to the empirical constants and that the rock avalanches considered here all have a close to constant effective friction of about 0.15 . This implies further that over a range of two orders of magnitude (from $2 \cdot 10^{6}$ to $90 \cdot 10^{6} \mathrm{~m}^{3}$ ), the effective coefficient of friction of rock avalanches is independent of volume. Consequently, our results suggest that the variation seen in Heim's ratio for these rock avalanches are not caused by a different basal friction, but by differing degrees of fragmentation. This shows that fragmentation plays a governing role in the runout of rock avalanches and should be included in hazard assessments.

\section{Conclusions}

We studied the dynamics of fragmenting rock avalanches experimentally in order to unravel the control of basal friction versus fragmentation on runout behaviour. We find that fragmentation causes both spreading and internal friction which compete on the control of avalanche dynamics. Based on energy arguments we derive a scaling law with empirical constants that quantifies the relative importance of spreading, internal and basal friction as a function of fragmentation. The scaling law approaches an extreme for which runout seems to be dominated by basal friction. The law is validated against a natural data set proving its universality and predictive power.

Data availability. The data for this paper is available as an open access data publication (Haug et al., 2020). 
Author contributions. OTH designed and run the experiments, derived the scaling law and wrote the first draft of the manuscript. MRo and $\mathrm{MRu}$ assisted in the experiments. MRo, KL and $\mathrm{OO}$ were involved in study design. All authors contributed to discussion and writing.

Competing interests. No competing interests are present.

Acknowledgements. The authors would like to thank to Frank Neumann and Thomas Ziegenhagen for construction and technical assistance.

The work has been supported by the Helmholtz Graduate Research School GEOSIM, the German Ministry for Education and Research (BMBF, FKZ03G0809A) and the Deutsche Forschungsgemeinschaft (DFG) through grant CRC 1114 "Scaling Cascades in Complex Systems" (No. 235221301) project B01. We thank Kirsten Elger and GFZ Data Services for publishing the data.

\section{Appendix A: Scaling law fit to experimental data only}

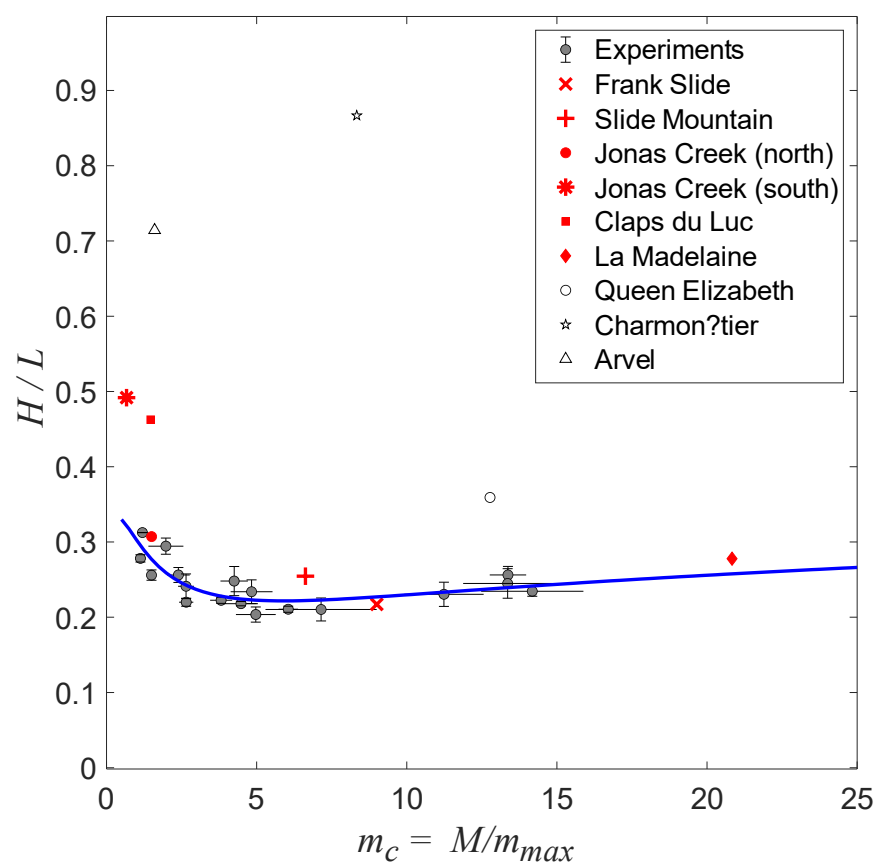

Figure A1. Heim's ratio and deposit length of experiments (this study) and natural rock avalanches (from Locat et al., 2006). The Heim's ratio of the analogue experiments (gray) and from the rock avalanches (red = selected set, open = discarded). The blue line represents the best fit of Equation 7 to experimental data with parameters $\alpha=0.11, \beta=0.68$ and $\gamma=2.0$. Data shown and a Matlab-script to plot them are available in Haug et al. (2020). 


\section{References}

Bowman, E. T., Take, W. A., Rait, K. L., and Hann, C.: Physical models of rock avalanche spreading behaviour with dynamic fragmentation, Can. Geotech. J., 49, 460-476, https://doi.org/10.1139/t2012-007, 2012.

Campbell, C. S.: Self-lubrication for long runout landslides, The Journal of Geology, 97, 653-665, http://www.jstor.org/stable/10.2307/ 30062196, 1989.

Davies, T. R. and McSaveney, M. J.: Runout of dry granular avalanches, Can. Geotech. J., 36, 313-320, https://doi.org/10.1139/t98-108, 1999.

De Blasio, F. V. and Crosta, G. B.: Fragmentation and boosting of rock falls and rock avalanches, Geophysical Research Letters, 42, 84638470, https://doi.org/10.1002/2015GL064723, 2015.

Gao, G., Meguid, M. A., Chouinard, L. E., and Zhan, W.: Dynamic disintegration processes accompanying transport of an earthquake-induced landslide, Landslides, pp. 1612-5118, https://doi.org/10.1007/s10346-020-01508-1, https://doi.org/10.1007/s10346-020-01508-1, 2020.

Haug, Ø. T., Rosenau, M., Leever, K., and Oncken, O.: Modelling Fragmentation in Rock Avalanches, Landslide Science for a Safer GeoEnvironment, 2, https://doi.org/10.1007/978-3-319-05050-8_16, 2014.

Haug, Ø. T., Rosenau, M., Leever, K., and Oncken, O.: On the Energy Budgets of Fragmenting Rockfalls and Rockslides: Insights from Experiments, Journal of Geophysical Research: Earth Surface, https://doi.org/10.1002/2014JF003406, http://doi.wiley.com/10.1002/ 2014JF003406, 2016.

Haug, Ø. T., Rosenau, M., Rudolf, M., Leever, K., and Oncken, O.: Laboratory model data from experiments on fragmenting analogue rock avalanches, https://doi.org/http://doi.org/10.5880/GFZ.2020.004, https://dataservices.gfz-potsdam.de/panmetaworks/review/ 2dfece6228dbb2d7ea320457abfeeb3f5c4a1e76f8a8d48c26ae4d0c7794702f/, 2020.

Heim, A.: Der Bergsturz von Elm., Zeitschrift der Deutschen Geologischen Gesellschaft, pp. 74-115, 1882.

Hsü, K. J.: Catastrophic debris streams (sturzstroms) generated by rockfalls, Geological Society of America Bulletin, 86, 129-140, http: //bulletin.geoscienceworld.org/content/86/1/129.short, 1975.

Hungr, O., Leroueil, S., and Picarelli, L.: The Varnes classification of landslide types, an update, Landslides, 11, 167-194, https://doi.org/10.1007/s10346-013-0436-y, 2013.

Kent, P. E.: The transport mechanism in catastrophic rock falls, The Journal of Geology, 74, 79-83, http://www.jstor.org/stable/10.2307/ $30075179,1966$.

Knapp, S. and Krautblatter, M.: Conceptual Framework of Energy Dissipation During Disintegration in Rock Avalanches, Frontiers in Earth Science, 8, 263, https://doi.org/10.3389/feart.2020.00263, https://www.frontiersin.org/article/10.3389/feart.2020.00263, 2020.

Lin, Q., Cheng, Q., Li, K., Xie, Y., and Wang, Y.: Contributions of Rock Mass Structure to the Emplacement of Fragmenting Rockfalls and Rockslides: Insights From Laboratory Experiments, Journal of Geophysical Research: Solid Earth, 125, e2019JB019296, https://doi.org/10.1029/2019JB019296, https://agupubs.onlinelibrary.wiley.com/doi/abs/10.1029/2019JB019296, e2019JB019296 2019JB019296, 2020.

Locat, P., Couture, R., Leroueil, S., Locat, J., and Jaboyedoff, M.: Fragmentation energy in rock avalanches, Canadian Geotechnical Journal, 43, 830-851, https://doi.org/10.1139/t06-045, 2006.

Lucas, A., Mangeney, A., and Ampuero, J. P.: Frictional velocity-weakening in landslides on Earth and on other planetary bodies., Nature communications, 5, 3417, https://doi.org/10.1038/ncomms4417, http://www.ncbi.nlm.nih.gov/pubmed/24595169, 2014. 
195 Manzella, I. and Labiouse, V.: Empirical and analytical analyses of laboratory granular flows to investigate rock avalanche propagation, Landslides, https://doi.org/10.1007/s10346-011-0313-5, 2012.

Melosh, H. J.: Acoustic Fluidization : A New Geologic Process?, Journal of Geophysical Research, 84, 7513-7520, 1979.

Shreve, R. L.: Leakage and fluidization in air-layer lubricated avalanches, Geological Society of America Bulletin, 79, 653-658, https://doi.org/10.1130/0016-7606(1968)79, http://bulletin.geoscienceworld.org/content/79/5/653.short, 1968.

Staron, L. and Lajeunesse, E.: Understanding how volume affects the mobility of dry debris flows, Geophys. Res. Lett., 36, 2-5, https://doi.org/10.1029/2009GL038229, http://www.agu.org/pubs/crossref/2009/2009GL038229.shtml, 2009.

Vaunat, J. and Leroueil, S.: Analysis of Post-Failure Slope Movements within the Framework of Hazard and Risk Analysis, Natural Hazards, pp. 83-109, 2002.

Wang, Y. F., Dong, J. J., and Cheng, Q. G.: Velocity-dependent frictional weakening of large rock avalanche basal facies: Implications for 205 rock avalanche hypermobility?, Journal of Geophysical Research: Solid Earth, 122, 1648-1676, https://doi.org/10.1002/2016JB013624, https://agupubs.onlinelibrary.wiley.com/doi/abs/10.1002/2016JB013624, 2017.

Zhao, T., Crosta, G. B., Utili, S., and De Blasio, F. V.: Investigation of rock fragmentation during rockfalls and rock avalanches via 3D DEM analyses, Journal of Geophysical Research: Earth Surface, https://doi.org/10.1002/2016JF004060, http://doi.wiley.com/10.1002/ 2016JF004060, 2017.

210 Zhao, T., Crosta, G. B., Dattola, G., and Utili, S.: Dynamic Fragmentation of Jointed Rock Blocks During Rockslide-Avalanches: Insights From Discrete Element Analyses, Journal of Geophysical Research: Solid Earth, 123, 3250-3269, https://doi.org/10.1002/2017JB015210, https://agupubs.onlinelibrary.wiley.com/doi/abs/10.1002/2017JB015210, 2018. 